\title{
Dynamic behaviors of cylindrical shells with geometric imperfection
}

\author{
J F Jia, A D Lai, D L Rong, Z H Zhou and X S Xu ${ }^{a}$
}

State Key Laboratory of Structure Analysis for Industrial Equipment, International Research Center for Computational Mechanics, The Faculty of Vehicle Engineering and Mechanics, Dalian University of Technology, Dalian 116024, People's Republic of China

\begin{abstract}
For finding out the relationship between vibrational modes and geometric imperfections, the dynamic behavior of cylindrical shells with a local imperfection is analyzed by using numerical simulation of finite element method in this paper. The results show that there are some differences in vibrational modes between cylindrical shells with and without imperfections. They appear that main corrugation of the mode of the higher orders for the shell with a local imperfection can be fastened on the region of the imperfection but the low order ones. The results also show that the vibrational modes of shells depend upon the size, shape and location of the imperfections. The local vibrational modes are discovered and are more obvious for the imperfection of the larger size. These results are helpful to the design of engineering structures.
\end{abstract}

\section{Introduction}

The imperfection in structures is inevitable. Structures with imperfection can affect directly the strength, stability and dynamic characteristics of structures. Therefore, it is necessary to study and evaluate the errors and safety caused by the imperfection. In the problem of structures with imperfection, the influence of small geometric imperfection may be considered first. Theoretical approach is proposed for studying the free vibrations of orthotropic cylindrical shells (with small geometric imperfections) [1]. And an analysis method is performed for the nonlinear vibration of a simply supported FGM cylindrical shell with small initial geometric imperfection under complex loads [2]. In slightly larger imperfection, the geometric imperfection is described by specific functions. For beams, a one-dimensional imperfection model is used in the form of the product of trigonometric and hyperbolic functions to describe the various possible geometric imperfections, and the nonlinear vibration is studied for reinforced composite (FG-CNTRC) beams of imperfect shear deformable functionally graded carbon nanotube [3]. A new vibration model is provided which is a rotating cantilever pre-twisted panel with initial exponential function type geometric imperfection and it is pointed that the free vibration of the structures depends upon geometric parameters, imperfection size and location [4]. Based on higher order shear and normal deformation theory, a new non-polynomial is used, then the vibration response of gradient plates with initial geometric imperfections is analyzed according to the theory [5]. The effect of initial geometric imperfections on vibration frequencies is presented for cylindrical shells aid theoretical, numerical and experimental methods [6-8]. By employing the finite element method, nonlinear free

\footnotetext{
a Corresponding author: xsxu@dlut.edu.cn
}

vibration and transient response are studied for plates and shells with geometric imperfections [9-11]. The results show that the behavior of nonlinear vibration can be changed by the imperfections. However, the relationship between vibrational modes and geometric imperfections has not yet been revealed distinctly, and the mechanism needs to be made clear. For this goal, it is attempted to study the problem by using numerical simulation of finite element method in this paper.

\section{The fundamental problem and the model}

Consider an isotropic homogeneous cylindrical shell with a local imperfection, of which the length is $L$, the radius is $R$, the thickness is $h$. And the imperfection width is $l$, the depth is $d$, the circumferential angle is $\alpha$, the distance to the end is $x_{1}$ (see figure 1). The physical parameters of the model are as follows: elastic modulus is $E$, Poisson's ratio is $\mu$, density is $\rho$. The dynamic behaviors of the cylindrical shell model with different geometric imperfection are analyzed in the paper by finite element method, including frequency and vibration mode.

\section{Comparisons with experimental and analytical results}

In order to verify the feasibility of finite element method, the finite element results are compared with the experimental results and the analytical solutions obtained by energy method [12]. The geometric and physical parameters of the model used for comparison are $L=0.2504 \mathrm{~m}, \quad h=0.0381 \mathrm{~m}, \quad R=0.09525 \mathrm{~m}, \quad E=207 \mathrm{GPa}$, $\mu=0.28, \rho=7860 \mathrm{Kg} / \mathrm{m}^{3}$. And the cylindrical shell behaves as a free-body. The circumferential modes $n=1-5$ and the 
longitudinal mode $\mathrm{m}=3$ (for the definition of $\mathrm{n}$ and $\mathrm{m}$, see Ref. [12]) are chosen for comparisons (see table 1). Compared with the experimental results, the maximum error of finite element method is $3.03 \%$. It can be found that the results of finite element numerical simulation are very close to those of experiments and analytical solutions, which shows that the finite element method is feasible.
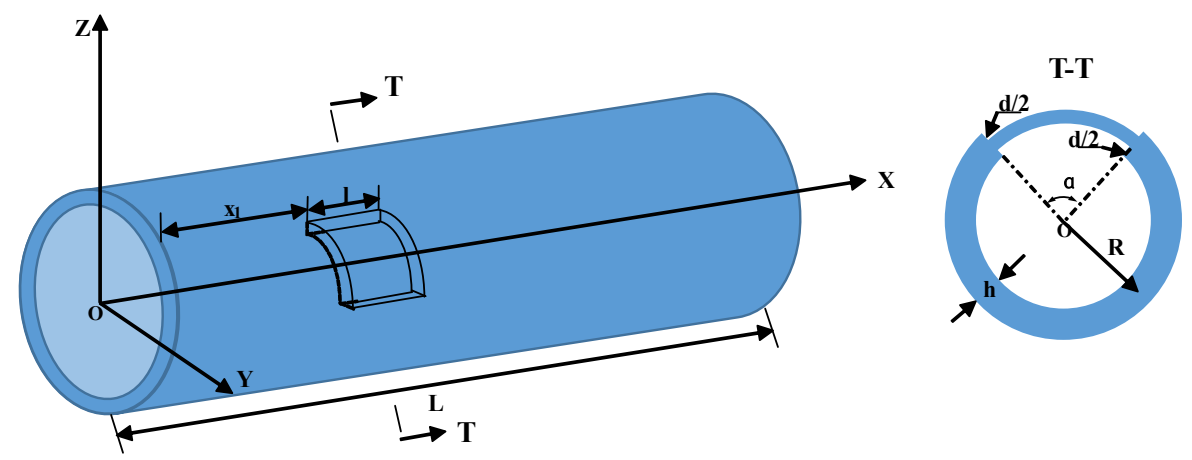

Figure 1. Schematic diagram of a cylindrical shell with a local imperfection

Table 1. Frequencies comparison of $n=1-5, m=3$. [Hz]

\begin{tabular}{ccccccc}
\hline $\mathrm{n}$ & 0 & 1 & 2 & 3 & 4 & 5 \\
\hline Present & 10974 & 10774 & 9507 & 12460 & 15925 & 20109 \\
Calculated[12] & 10719 & 10770 & 9521 & 12584 & 16435 & 20801 \\
Expt.[12] & 10874 & 10803 & 9588 & 12717 & 16391 & 20737 \\
\hline
\end{tabular}

Table 2. Vibration frequencies of $n=0-11, m=1-4$. [Hz]

\begin{tabular}{crrrc}
\hline $\mathrm{m}$ & \multicolumn{1}{c}{1} & \multicolumn{1}{c}{3} & \multicolumn{1}{c}{4} \\
\hline $\mathrm{n}=0$ & 159.359 & 256.114 & 318.754 & 478.221 \\
$\mathrm{n}=1$ & 85.279 & 181.213 & 290.128 & 396.510 \\
$\mathrm{n}=2$ & 36.425 & 87.381 & 150.785 & 219.718 \\
$\mathrm{n}=3$ & 26.327 & 50.862 & 87.889 & 132.198 \\
$\mathrm{n}=4$ & 37.984 & 46.815 & 65.661 & 92.691 \\
$\mathrm{n}=5$ & 59.334 & 62.595 & 70.700 & 84.855 \\
$\mathrm{n}=6$ & 86.699 & 88.346 & 92.221 & 99.3125 \\
$\mathrm{n}=7$ & 119.503 & 120.632 & 122.995 & 127.079 \\
$\mathrm{n}=8$ & 157.719 & 158.643 & 160.431 & 163.275 \\
$\mathrm{n}=9$ & 201.398 & 202.262 & 203.822 & 206.109 \\
$\mathrm{n}=10$ & 250.699 & 251.615 & 253.009 & 255.014 \\
$\mathrm{n}=11$ & 305.808 & 306.820 & 308.102 & 309.916 \\
\hline
\end{tabular}

\section{Free vibration characteristics of perfect elastic cylindrical shell}

The model studied in the paper use steel material, whose $\mathrm{E}=206 \mathrm{GPa}, \mu=0.3, \rho=7800 \mathrm{Kg} / \mathrm{m}^{3}, \quad \mathrm{~L}=10 \mathrm{~m}, \mathrm{R}=1 \mathrm{~m}$, $\mathrm{d}=0.01 \mathrm{~m}$. The both ends of the model are fixed. For frequencies and modes, define the number of circumferential corrugation is order $n$, the number of axial corrugation is branch $\mathrm{m}$. By finite element method, the frequencies of the first four branches whose order is 0 (axisymmetric case) to 11 are shown in table 2. And the vibration modes of different orders and branches are shown in figure 2 .

\section{Free vibration frequencies for cylindrical shells with geometric imperfection}

For studying vibration frequencies of cylindrical shells with geometric imperfection, multiple cases of imperfections are discussed. The results are shown in table 3. In Case 1, the location of imperfection is $x_{1}=4.5 \mathrm{~m}$, and the imperfection width is $l=1 \mathrm{~m}$, angle is $\alpha=2 \pi$. Case 2 represents $x_{1}=2 \mathrm{~m}, l=1 \mathrm{~m}$, angle is $\alpha=2 \pi$. Similarly, in Case $3, x_{1}=3.5 \mathrm{~m}, l=3 \mathrm{~m}, \alpha=2 \pi$. Imperfection in Case 4 is $x_{1}=4.5 \mathrm{~m}, l=1 \mathrm{~m}, \alpha=\pi$. In Case 5, $x_{1}=4.5 \mathrm{~m}, l=1 \mathrm{~m}, \alpha=\pi / 4$.

Table 3 presents the lowest $(\mathrm{m}=1)$ vibration frequencies corresponding to the first 11 modes under imperfections of different depths, widths locations and angles. The results show that imperfection have less impact on lower-order frequencies but larger on higherorders. And the larger the imperfection size (including depth, width and angle), the more the impact. Furthermore, for higher-order frequencies, the vibration frequencies of the shell with imperfection are generally lower than that without imperfection, and as the order increases, the frequency difference is larger and larger. When $n=11$ and the imperfection size is the largest, the difference reaches a maximum of $74.44 \%$. 


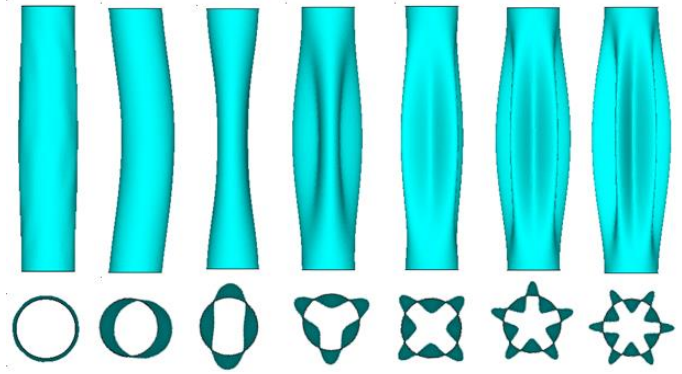

(a) $n=0-9, m=1$.

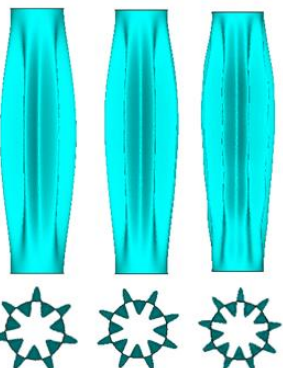

Figure 2. Vibration modes
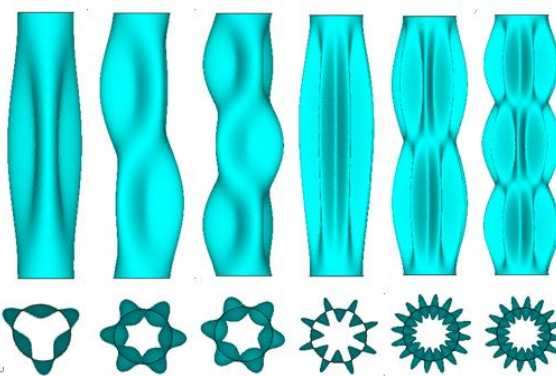

(b) $\mathrm{n}=3,8, \mathrm{~m}=1,2,3$.

Table 3. Frequencies of $n=0-11, m=1$. [Hz]

\begin{tabular}{cccccccc}
\hline $\mathrm{n}$ & & 0 & 1 & 2 & 3 & 4 & 5 \\
\hline Perfect cylindrical shell & 159.359 & 85.279 & 36.425 & 26.327 & 37.984 & 59.334 \\
\hline $\mathrm{d} / \mathrm{h}=1 / 4$ & Case1 & 163.397 & 86.838 & 36.860 & 25.878 & 36.373 & 56.071 \\
& Case2 & 158.772 & 82.371 & 36.575 & 26.202 & 37.405 & 57.289 \\
& Case3 & 170.712 & 90.153 & 38.004 & 25.097 & 32.961 & 49.129 \\
& Case4 & 161.371 & 86.046 & 36.634 & 26.054 & 37.056 & 57.700 \\
& Case5 & 160.375 & 85.805 & 36.523 & 26.159 & 37.468 & 58.353 \\
\hline $\mathrm{d} / \mathrm{h}=3 / 4$ & Case1 & 172.237 & 87.547 & 36.260 & 25.585 & 36.338 & 55.878 \\
& Case2 & 148.012 & 81.213 & 35.958 & 26.179 & 37.487 & 57.191 \\
& Case3 & 203.059 & 103.328 & 42.835 & 26.451 & 31.043 & 38.448 \\
& Case4 & 165.728 & 86.135 & 36.254 & 25.799 & 36.672 & 56.721 \\
& Case5 & 162.628 & 85.117 & 36.256 & 26.024 & 37.113 & 57.416 \\
\hline Perfect cylindrical shell & 8 & 7 & 8 & 9 & 10 & 11 \\
\hline $\mathrm{d} / \mathrm{h}=1 / 4$ & Case1 & 79.699 & 119.503 & 157.719 & 201.398 & 250.699 & 305.808 \\
& Case2 & 80.302 & 106.566 & 135.734 & 168.039 & 203.842 & 243.855 \\
& Case3 & 68.851 & 92.490 & 135.736 & 167.960 & 203.847 & 243.860 \\
& Case4 & 83.215 & 113.273 & 146.000 & 152.494 & 188.899 & 229.574 \\
& Case5 & 84.917 & 116.698 & 154.368 & 193.342 & 239.842 & 288.579 \\
\hline $\mathrm{d} / \mathrm{h}=3 / 4$ & Case1 & 78.125 & 98.146 & 110.806 & 115.903 & 118.091 & 121.093 \\
& Case2 & 78.355 & 98.160 & 110.806 & 115.899 & 118.084 & 121.097 \\
& Case3 & 40.268 & 42.110 & 46.901 & 54.867 & 65.448 & 78.157 \\
& Case4 & 80.565 & 101.761 & 116.275 & 123.793 & 133.626 & 155.301 \\
& Case5 & 82.781 & 110.175 & 123.163 & 140.624 & 168.714 & 201.609 \\
\hline
\end{tabular}

Since the imperfection has a large influence on the higher-order frequencies, the situations of $n=8, m=1-6$ are chosen to study the changes of frequencies of different branches under imperfections of the same angle $\alpha=2 \pi$ and width $l=1 \mathrm{~m}$ (see figure 3 ). Results show the frequencies increases as the number of branches increases. In addition, the imperfection location, no matter whether on the center or the side of the cylindrical shell, has little effect on frequency.

\section{Free vibration modes for cylindrical shells with geometric imperfection}

The cylindrical shell modes with the imperfection of the largest size (ratio of imperfection depth to shell thickness $d / h=3 / 4$, angle $\alpha=2 \pi$, location $x_{1}=3.5 \mathrm{~m}$, width $l=3 \mathrm{~m}$ ) in all cases are chosen to compare the modes with perfect cylindrical shell as figure 4 . According to the comparison, it can be found that a local geometric imperfection has a more influence on the vibration modes of high orders, but it has little effect on the low-order modes. Thus, only the effect of imperfections of higher-order modes will be shown in the following.

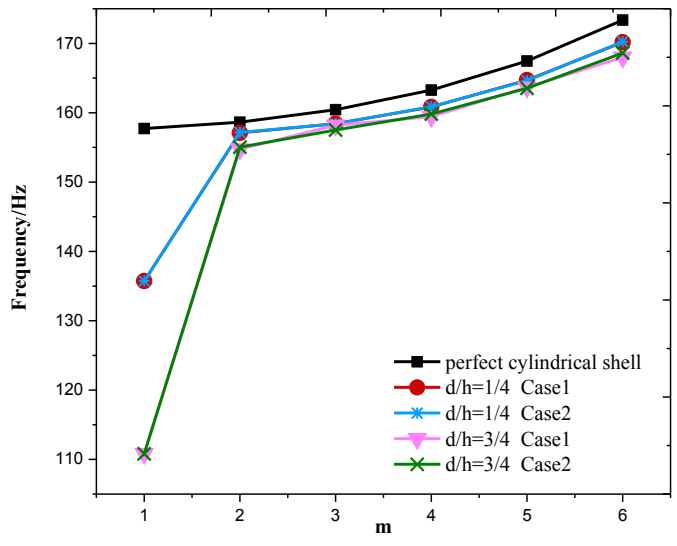

Figure 3. Frequencies of $n=8, m=1-6 .[\mathrm{Hz}]$ 


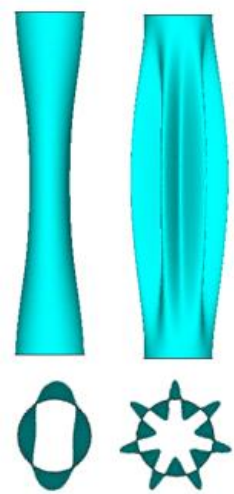

(a) perfect shell

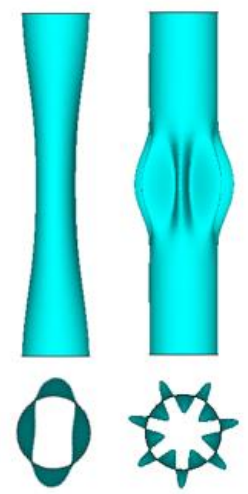

(b) imperfect shell
Figure 4. Vibration modes of $n=2,7, m=1$.

The modes of $n=7,8,9, m=1$ are shown in figure 5 . In this figure, both in (a) and (b), the angle of imperfection is $\alpha=2 \pi$, location $x_{1}=4.5$, width $l=1$. The difference is that the imperfection depth is in (b) is 3 times that of (a). And the frequencies corresponding to the modes in (a) are $\omega=106.566 \mathrm{~Hz}, 135.734 \mathrm{~Hz}, 168.039 \mathrm{~Hz}$, which in (b) are $\omega=98.146 \mathrm{~Hz}, 110.806 \mathrm{~Hz}, 115.903 \mathrm{~Hz}$. As the figure shows, far from the imperfection, the amplitude is almost zero. And the deeper the imperfection, the more concentrated the corrugations are within region of the imperfection.

Imperfection in figure 6 is all at the condition of $\alpha=2 \pi$, $d / h=1 / 4$, and these vibration modes as the picture shows are order $n=8$, branch $m=1,3,5$. The width of imperfection in (b) is 3 times that of (a). The frequencies corresponding to the modes shown in figure 6 are $\omega=135.734 \mathrm{~Hz}$, $158.424 \mathrm{~Hz}, 164.711 \mathrm{~Hz}, 120.350 \mathrm{~Hz}, 147.714 \mathrm{~Hz}$ and $160.325 \mathrm{~Hz}$ respectively. It can be found that corrugations will change significantly at the imperfection.

Figure 7 presents modes of the same order and branches as figure 6 . And imperfection in (a) and (b) is $\alpha=2 \pi, d / h=3 / 4, l=1$, besides, the imperfection in (a) is at the center of the cylindrical shell, but that in (b) is on one side. Their frequencies are $\omega=110.831 \mathrm{~Hz}, 158.184 \mathrm{~Hz}$, $163.675 \mathrm{~Hz}, 110.806 \mathrm{~Hz}, 157.502 \mathrm{~Hz}, 163.533 \mathrm{~Hz}$ respectively. It is clear that the position of the imperfection has a large influence on the vibration modes, and the vibration corrugations have visible changes at the imperfections at different positions.

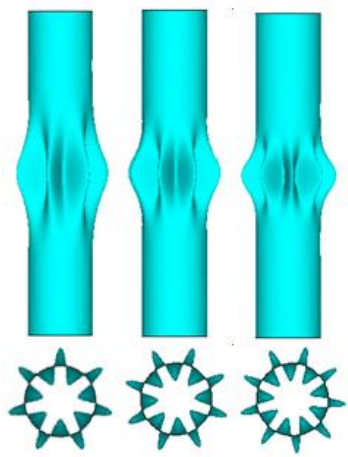

(a) $d / h=1 / 4$

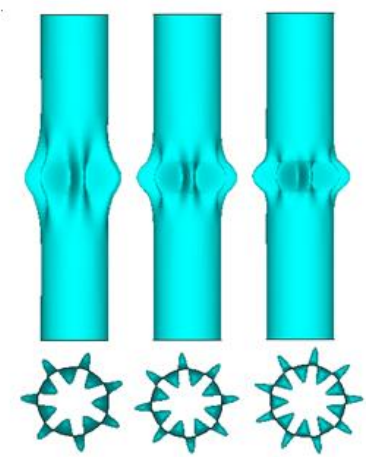

(b) $d / h=3 / 4$
Figure 5. Vibration modes of $n=7,8,9, m=1$

Figure 8 shows modes of order $n=6,7,8$ of imperfections at the same thickness, location and width $\left(d / h=3 / 4, \quad x_{1}=4.5 \mathrm{~m}, l=1 \mathrm{~m}\right)$ when branch $\mathrm{m}=1$, the frequencies of which are $\omega=80.565 \mathrm{~Hz}, 101.761 \mathrm{~Hz}$, $116.275 \mathrm{~Hz}, 82.781 \mathrm{~Hz}, 110.175 \mathrm{~Hz}$ and $123.163 \mathrm{~Hz}$. The imperfection angle in (a) is $\pi$, that in (b) is $\pi / 4$. By observing these maps, it can be seen the deformation is only concentrated in the imperfection area, and there is almost no deformation outside the imperfection.

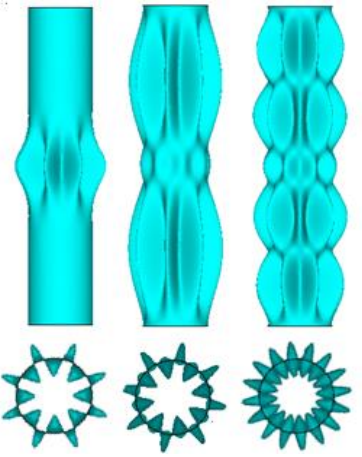

(a) $x_{1}=4.5 \mathrm{~m}, l=1 \mathrm{~m}$

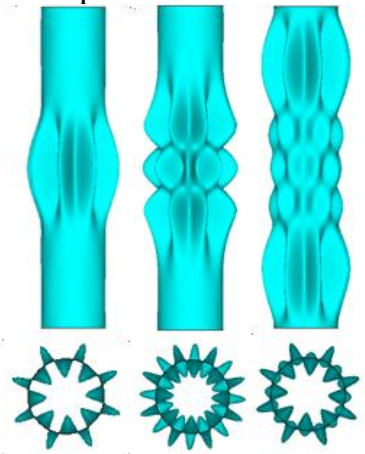

(b) $x_{1}=3.5 \mathrm{~m}, l=3 \mathrm{~m}$
Figure 6. Vibration modes of $n=8, m=1,3,5$.

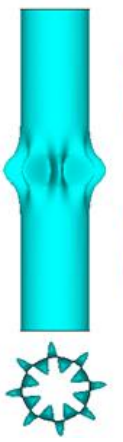

(a) $x_{1}=4.5 \mathrm{~m}, l=1 \mathrm{~m}$
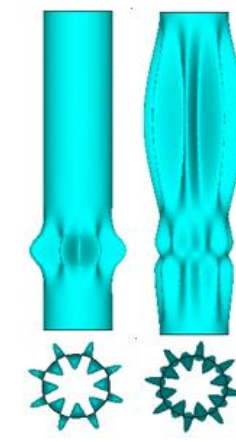

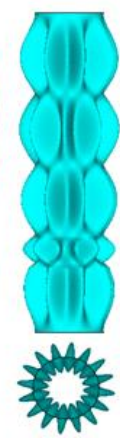

(b) $x_{1}=2 \mathrm{~m}, l=1 \mathrm{~m}$
Figure 7. Vibration modes of $n=8, m=1,3,5$

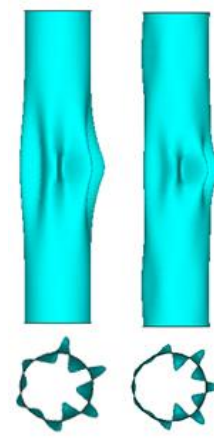

(a) $\alpha=\pi$
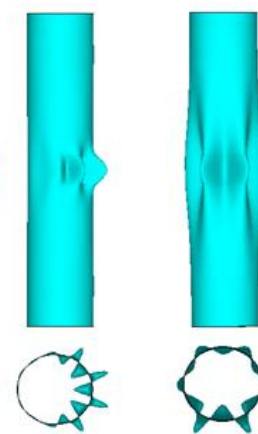

(b) $\alpha=\pi / 4$
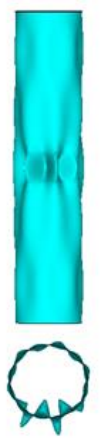

Figure 8. Vibration modes of $\mathrm{n}=6,7,8, \mathrm{~m}=1$.

\section{Acknowledgments}

The supports of Dalian Innovation Foundation of Science and Technology (No. 2018J11CY005) and Shenzhen Science and Technology Funding Fundamental Research Program (No. JCYJ20170413 141248626) are gratefully acknowledged.

\section{Summary}

Dynamic behavior of cylindrical shells with a local geometric imperfection is different from the shells 
without imperfection. It includes vibrational frequencies and modes. The phenomenon has been found that the imperfections have some influence on the vibration characteristics of cylindrical shells, both for frequencies and modes. Specially, it is more obvious for large-scale imperfections. For the frequency, the results show that imperfection have less impact on the lower-order frequencies but the higher-orders. The frequencies of higher-orders are much lower than the frequencies without imperfection. Besides, the modes display a phenomenon, which the corrugation tends to concentrate on the imperfection location for frequencies of higherorders. The results show also that the frequency increases with the number of branches and the corrugation is the more complex on the imperfection location for corresponding modes. In addition, frequencies and modes are directly affected by the location, size and depth of the imperfection. These conclusions and results are potential to be used as a design reference for structures with similar geometry.

\section{References}

1. Kubenko V D, Koval'chuk P S 2017 Int. Appl. Mech. 53 121-9.

2. Liu Y Z, Hao Y X, Zhang W, Chen J and Li S B 2015 J. Sound Vibr. 348 294-328.

3. Wu H L, Yang J, Kitipornchai S 2016 Compos. Pt. BEng. 90 86-96.

4. Gu X J, Hao Y X, Zhang W, Liu L T and Chen J 2019 Appl. Math. Model. 68 327-52.

5. Gupta A, Talha M 2016 Compos. Pt. B-Eng. 107 141-61.

6 Wedel-Heinen J 1991 Int. J. Solids Struct. 27(1) 2947.

7. Hui D, Du I H Y 1986 J. Appl. Mech. 53(3) 675-80.

8. Labans E, Bisagni C 2019 Compos. Struct. 210 44657.

9. Nanda N, Pradyumna S 2011 J. Compos Mater. 45 2103-12.

10. Mirjavadi S S, Afshari B M, Barati M R and Hamouda A M S 2019 Microsyst. Technol. 1-14.

11. Chen C S, Tan A H 2007 Compos. Struct. 78(4) 52936.

12. Singal R K, Williams K 1988 J. vib. acoust. stress reliab. des. 186(4) 502 